Proc. Earth Planet. Sci., Vol. 90, No. 4, Decomber 1981, pp. 437-460. (c) Printed in India.

\title{
Application of solid state nuclear track detectors in fission studies*
}

\author{
R H IYER \\ Nuclear Materials Accounting Cell, Bhabha Atomic Research Centre, \\ Bombay 400085 , India
}

\begin{abstract}
Solid state nuclear track detectors (SSNTD) were introduced as an important research tool in nuclear science and technology in the early 1960s. In this paper an attempt is made to give an overview of some of the important applications of SSNTO in the study of fission-related phenomena. The areas covered are: (a) spontaneous fission half-lives, (b) compound nuclear life-time measurements, (c) fission cross-section, excitation functions and fission fragment angular distributions, (d) fission isomers, (e) search for superheavy elements and (f) absolute fission yield measurements. In each case a few examples of experimental work carried out in various laboratories including the Bhabha Atomic Research Centre (BARC), Bombay are discussed to highlight the significant contributions these studies have made to our understanding of nuclei and nuclear fission. The important role played by SSNTD in each of the above areas of fission studies is illustrated. Some specific cases are cited where the innovative use of SSNTD has lead to results of profound significance in fission physics. A general review of the impact of these studies on our present understanding of nuclei and nuclear fission as well as a brief outline of the problems and future prospects are also given in the paper.
\end{abstract}

Keywords. Tracks; fission; half-lives; cross-section; excitation function; isomers; superheavy elements.

\section{Introduction}

Solid state nuclear track detectors (SSNTD) were introduced as an important tool in nuclear science and technology in the early 1960s (Fleischer et al 1965). They are dielectric materials such as mica, glass, synthetic plastics etc. which record and permanently store the trajectory of fast-moving charged particles. The stored information contained in the trajectory of the charged particles can be conveniently retrieved by the experimenter by selective chemical etching and observation under an optical microscope. The extreme simplicity of the technique coupled with the lack of dependence on costly electronics on the one hand and the availability of a variety of detectors with different sensitivities to charged particles on the other make them particularly useful in the investigation of rare and low cross-section events in an essentially background-free situation. By merely counting the number of tracks (recorded on a detector) of charged particles ejected from a nuclear reaction, one can do experiments in nuclear physics and chemistry, particle dosimetry and microanalysis (Fleischer et al 1972). There is hardly any branch of science and technology where SSNTDs do not have an actual or potential application. Today, the technique has developed from a mere laboratory curiosity into one of the cheapest and most powerful expeirmental tools in the study of a number of nuclear phenomena (Fleischer et al 1975). Its growth in the last

* Paper precented at the second national seminar-cum-workshop on the use and application of solid state nuclear track detectors held at Physical Research Laboratory, Ahmedabad, India, during 24-26 Fobruary 1981 
15 years, both in size and applications has been spectacular. Over fifty laboratories around the world make use of this technique for various experimental work which has led to the growth of fundamental knowledge and technological applications. Many review articles cataloging the diverse applications of the technique are available in the literature (Fleischer et al 1965, 1972, 1975).

Precision measurements in scientific research have generally come through the use of expensive instruments. But the SSNTD technique, also called track-etch technique has made precision measurements on the detection and measurement of neutron and charged particle-induced nuclear reactions so inexpensive that even small laboratories with some basic facilities can take up R \& D work using this technique.

In this paper we shall discuss some of the important applications of the technique to fission-related studies by citing examples of experimental work carried out in various laboratories including those carried out at our research centre and highlight the significant contributions these studies have made to our understanding of nuclei and nuclear fission. The topics covered are: (a) measurement of spontaneous fission half-lives, (b) measurement of life-times of compound nuclei, (c) fission cross-sections, angular distribution of fission fragments and fission excitation functions, (d) investigations on fission isomers, (e) search for super heavy elements and (f) absolute fission yield measurements. It is not practicable to give an exhaustive coverage of each topic for the simple reason that the experimental and theoretical data reported in the literature are too voluminous. Instead, one or two examples will be discussed in each case to illustrate how SSNTD has played a key role. A general review of the impact of these and related studies on our understanding of nuclei and nuclear fission is also given here.

\section{Special features of SSNTD}

Before discussing specific applications of SSNTD, let us very briefly examine some of their special features (apart from their simplicity and inexpensive nature) which make them extremely valuable for studies related to the fission process:

(i) they are insensitive to high background radiation making investigations on specific, rare and low cross-section nuclear reactions possible.

(ii) a wide variety of detectors with different sensitivities to charged particles are available for the experimenter to choose from to meet his specific experimental needs.

(iii) the integrating nature of the detectors allows events to be accumulated over large periods of time without any deterioration of the detector.

(iv) they are amenable to different geometrical arrangements such as $2 \pi, 4 \pi$, forward and backward recoil geometry etc.

(v) they can be used in any size; small sizes allow them to be used in remote and difficult-to-reach experimental locations.

(vi) it is a non-electronic technique; so no electronic break downs to worry about.

These features of SSNTD, coupled with some ingenuity on the part of the investigator make them unique among the experimental tools that are generally employed in fission studies. 


\section{Applications to fission-related studies}

\subsection{Measurement of spontaneous fission half-lives}

Spontaneous fission from the ground state is an important mode of decay of heavy elements with atomic number $Z 90$ and above. It occurs with measurable decay rate in elements from uranium up, the half-lives decreasing rapidly with increasing $Z$. Table 1 shows some typical data to illustrate the wide range of spontaneous fission half-lives. A precise knowledge of the spontaneous fission half-lives of heavy elements is important from the point of view of basic understanding of nuclear structure, checking existing theories of fission and alpha decay systematics, predicting the properties of new heavy elements and extending the periodic table to regions covering the yet undiscovered superheavy elments. From purely practical considerations, the spontaneous fission decay constant of ${ }^{238} \mathrm{U}$ is a basic parameter needed in geochronology. Many current techniques of assay of heavy elements, require a knowledge of their decay properties; these are linked with nuclear safeguards, plutonium recycle, and accounting and management of nuclear materials.

Solid state nuclear track detectors have been used very effectively in the accurate measurement of both extremely large and extremely short spontaneous fission halflives (Hulet et al 1971; Khan and Durrani 1973; see table 1). When one considers spontaneous fission decay of heavy elements it is important to realise that alpha

Table 1. Spontaneous fission half-lives of some heavy element isotopes-typical data*

\begin{tabular}{|c|c|c|c|}
\hline Nuclide & $Z$ & $t_{1,2}(\mathrm{SB})$ & Remarks \\
\hline${ }^{232} \mathrm{Th}$ & 90 & $\sim 10^{21} \mathrm{y}$ & \\
\hline${ }^{231} \mathrm{~Pa}$ & 91 & $10^{10} \mathrm{y}$ & \\
\hline${ }^{285} \mathrm{U}$ & 92 & $1.9 \times 10^{17} y$ & $\mathbf{a}$ \\
\hline${ }^{238} \mathrm{U}$ & 92 & $1.02 \times 10^{10} \mathrm{y}$ & $\mathbf{a}$ \\
\hline${ }^{137} \mathrm{~Np}$ & 93 & $3.0 \times 10^{18} \mathrm{y}$ & $\mathbf{a}$ \\
\hline${ }^{288} \mathrm{Pu}$ & 94 & $4.6 \times 10^{10} \mathrm{y}$ & $\mathbf{a}$ \\
\hline${ }^{241} \mathrm{Am}$ & 95 & $1.15 \times 10^{14} y$ & $\mathbf{a}$ \\
\hline${ }^{244} \mathrm{Cm}$ & 96 & $10^{7} \mathrm{y}$ & $\mathbf{a}$ \\
\hline${ }^{240} \mathrm{Bk}$ & 97 & $1.65 \times 10^{\circ} \mathrm{y}$ & a \\
\hline${ }^{848} \mathrm{Cf}$ & 98 & $3 \times 10^{4} y$ & $\mathbf{a}$ \\
\hline${ }^{252} \mathrm{Cf}$ & 98 & $85 \mathrm{y}$ & $\mathbf{a}$ \\
\hline${ }^{260} \mathrm{Cf}$ & 98 & $740 \mathrm{sec}$ & \\
\hline${ }^{268} \mathrm{Es}$ & 99 & $6.3 \times 10^{6} y$ & \\
\hline${ }^{257} \mathrm{Fm}$ & 100 & $125 \mathrm{y}$ & \\
\hline${ }^{268} \mathrm{Fm}$ & 100 & $380 \mu$ sec. & $\mathbf{a}$ \\
\hline${ }^{269} \mathrm{Fm}$ & 100 & $1 \cdot 5 \mathrm{sec}$. & \\
\hline${ }^{259} \mathrm{Md}$ & 101 & $5700 \mathrm{sec}$. & \\
\hline${ }^{259} \mathrm{No}$ & 102 & $8.6 \mathrm{sec}$ & $\mathbf{a}$ \\
\hline${ }^{256}$ No & 102 & $1500 \mathrm{sec}$. & a \\
\hline${ }^{258} 104$ & 104 & 11 milli sec. & $\mathbf{a}$ \\
\hline${ }^{861} 105$ & 105 & $1.8 \mathrm{sec}$ & $\mathbf{a}$ \\
\hline${ }^{202} 105$ & 105 & 28 sec. & $\mathbf{a}$ \\
\hline
\end{tabular}

*Source of data: Fleischer et al 1975; Gay and Sher 1975; Hoffman 1979.

a-sSNTDs have been used (Fleischer et al 1975.) 
decay is a competitive process. Consequently, the heavy element isotopes are associated with intense alpha activity causing problems in handling and those arising from pile-up alpha pulses (Gay and Sher 1975). For example, the ratio of alpha to spontaneous fission decay of ${ }^{238} \mathrm{Pu}$ is about $5 \times 10^{8}$. The determination of long SF lifetimes require fairly large amounts of the isotope and large observation (exposure) times. In such situations the integrating nature of SSNTD coupled with their insensitivity to alpha particles (mica in particular) are major advantages over the conventional electronic techniques.

The principle for the conventional and simplest use of the technique for the measurement of fairly long spontaneous fission half-lives is well established (Fleischer and Price 1964; Khan and Durrani 1972; Gay and Sher 1975) . For example, in the determination of the spontaneous fission decay constant of ${ }^{238} \mathrm{U}$, a natural uranium source in the form of a thin metal foil or in the form of an electroplated source is kept in direct contact with a track detector (usually mica) for a sufficiently long period of time to accumulate a statistically significant number of spontaneous fission tracks. The number of tracks recorded can be expressed as:

$$
(\text { track })_{\mathrm{SF}}=K \cdot N_{8} \cdot \lambda_{\mathrm{SF}} \cdot t_{\mathrm{SF}}
$$

where $\quad K$ is the track registration efficiency for the source-detector assembly, $N_{8}$ is the number of ${ }^{238} \mathrm{U}$ atoms exposed to the detector, $\lambda_{\mathrm{SF}}$ is the spontaneous fission decay constant of ${ }^{238} \mathrm{U}$ and $t_{\mathrm{SF}}$ is the exposure time.

In order to eliminate the need for knowing the track registration efficiency, $K$, a second exposure of the source detector assembly is carried out with thermal neutrons using a fresh detector. The detector records induced fission tracks from the thermal neutron fission of ${ }^{235} \mathrm{U}$ which can be expressed as

(tracks) $)_{\mathrm{irr}}=K \cdot N_{5} \cdot \sigma_{f} \cdot \phi t_{\mathrm{irr}}$

where $N_{5}$ is the number of atoms of ${ }^{235} \mathrm{U}$ in the source, $\sigma_{j}$ is the thermal neutron fission cross-section of ${ }^{235} \mathrm{U}, \phi$ is the thermal neutron flux and $t_{\mathrm{irr}}$ is the irradiation time. Then

$$
\frac{(\text { tracks })_{\mathrm{irr}}}{(\text { tracks })_{\mathrm{SF}}}=\frac{N_{5}}{N_{8}} \cdot \frac{\sigma_{f} \cdot \phi}{\lambda_{\mathrm{SF}}} \cdot \frac{t_{\mathrm{irr}}}{t_{\mathrm{SF}}} .
$$

All the quantities in the above equation are known except $\lambda_{\mathrm{SF}}$ which can be determined.

A couple of illustrative examples of the ingenious uses of SSNTD to measure extremely short SF life-times and which have made a profound impact on nuclear structure, nuclear stability and fission systematics are outlined below. As already pointed out, spontaneous fission half-lives decrease rapidly with increasing atomic number. One of the serious problems associated with the study of very heavy actinide elements with $Z>98$ is their very short half-lives and low production cross-sections. Until about 1973, the heaviest nuclide whose fission properties were studied in some detail was ${ }_{100}^{257} \mathrm{Fm}$ (Hoffman 1979). With the availability of small quantities of isotopes of very heavy actinides through heavy ion reactions, fission properties of heavier actinide isotopes have recently been investigated particularly at the Los Alamos Scientific 
Laboratory, the Lawrence Livermore Laboratory, the University of California, Berkeley and the Oak Ridge National Laboratory (Ferguson et al 1979).

Hulet et al (1971) used a 'rotating drum method' to determine the spontaneous fission half-life of ${ }_{100}^{258} \mathrm{Fm}$. The experimental arrangement is shown in figure 1. Atoms of ${ }^{258} \mathrm{Fm}$ were produced by bombarding a weightless target of ${ }_{100}^{257} \mathrm{Fm}$ (about $10^{9}$ atoms electrodeposited on a $0.013 \mathrm{~mm}$ thick beryllium foil) with $12.5 \mathrm{MeV}$ deuterons by the ${ }^{257} \mathrm{Fm}(d, p){ }^{258} \mathrm{Fm}$ reaction. The atoms of ${ }^{258} \mathrm{Fm}$ formed, recoil out of the target and get deposited on a steel drum. The irradiation is stopped and the drum is rotated at a known high speed (1500-3275 rpm). The fission fragments resulting from the spontaneous fission of ${ }^{258} \mathrm{Fm}$ are caught in a series of mica strips which record the fission tracks. Several runs were performed to accumulate enough spontaneous fission events. From the speed of rotation of the drum and the variation of fission track density in the mica strips, the half-life was estimated. Figure 2 shows the experimental results which indicate a SF half-life of $380 \pm 60 \mu$ sec for ${ }^{258} \mathrm{Fm}$.

An equally ingenious experimental arrangement, the 'moving belt method' was used by Flerov et al (1964) at Dubna to obtain possible evidence of an isotope of the element 104. Atoms of the element 104 were produced by bombarding thin $\left(700 \mu \mathrm{g} / \mathrm{cm}_{z}\right.$ covered with $100 \mu \mathrm{g} / \mathrm{cm}^{2}$ of nickel) targets of ${ }_{94}^{242} \mathrm{Pu}$ with ${ }^{22} \mathrm{Ne}$ ions. The recoiling product atoms from the reaction ${ }^{242} \mathrm{Pu}\left({ }^{22} \mathrm{Ne}, 4 \mathrm{n}\right){ }_{104}^{260}$ were caught in a conveyer belt about $8 \mathrm{~m}$ long. At the end of the bombardment, the belt moves at a known high speed and the fission fragments resulting from the spontaneous fission of element 104 are caught in phosphate glass detectors which record the fission tracks. Here again, the half-life is estimated from the variation in track density and from a knowledge of the speed of the moving belt. The experimental arrangement is shown in figure 3 . From this experiment a half-life of $0.3 \mathrm{sec}$ was estimated for element 104 .

Both the 'rotating drum-SSNTD' and the 'moving belt-SSNTD' systems have played a major role in the detection and identification of trans-fermium isotopes and are standard experimental tools in all leading research centres in the world engaged in the search for very heavy and superheavy elements.

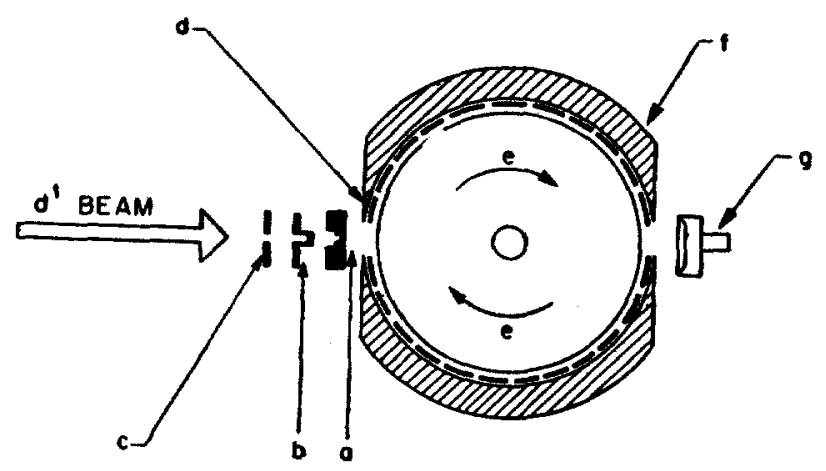

Figure 1. Schematic representation of the target and drum-mica system for measurement of short spontaneous fission (SF) half-life. Deuterons strike the ${ }^{25}$ Fm target (a) after passing through aluminium degrading foils (b) and tantalum collimator (c). The atoms of ${ }^{258} \mathrm{Fm}$ recoiling from the target are caught on the surface of the rotating drum (e) and their decay by SF is recorded in short strips of mica (d) attached in a continuous band to the drum housing (f). An $a$-detector ( $g$ ) was used for monitoring the recoil efficiency of the target (Hulet et al 1971). 


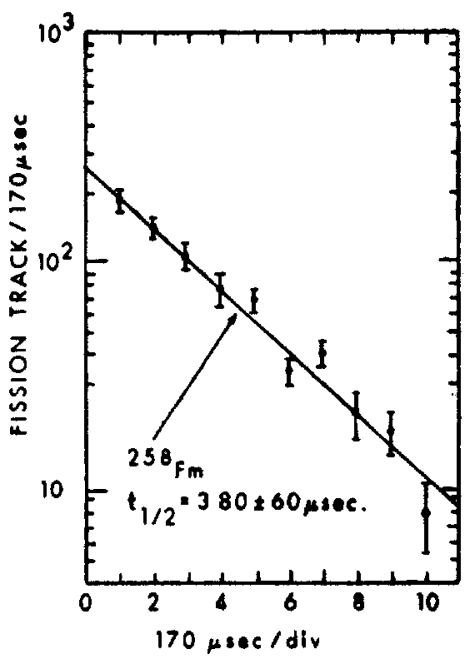

Figure 2. Decay curve for spontaneous fission assigned to ${ }^{258} \mathrm{Fm}$. Net fission tracks from five bombardments have been summed (Hulet et al 1971).

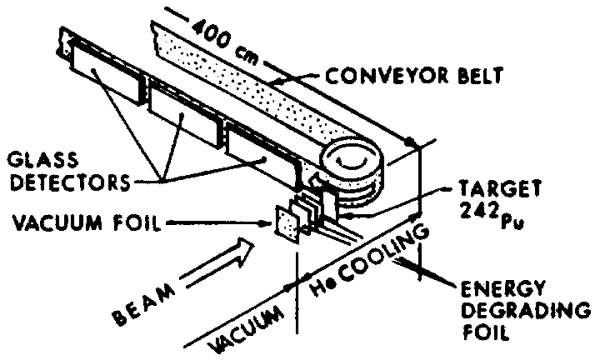

Figure 3. The scheme of the arrangement used in the experiments on the synthesis of element 104: The moving belt-sSNTD system (Flerov et al 1964).

Let us now briefly discuss the impact of these experiments, particularly the experimental results on ${ }^{258} \mathrm{Fm}$, on fission physics.

The available information on the spontaneous fission half-lives of actinide and transactinide elements has been used to establish certain systematic trends for even-even isotopes (Nurmia et al 1967). While the $t_{1 / 2}$ (SF) generally decrease with increasing $Z$, a definite stabilising effect for 152 neutrons has been observed, beginning with curium. These calculations reproduce the general trends very well but can show large deviations for a given nuclide (Randrup et al 1976; Baran 1978; Baran et al 1979). The experimental value for the $t_{1 / 2}(\mathrm{SF})$ of ${ }^{258} \mathrm{Fm}$ of $380 \mu \mathrm{sec}$ was lower than the predicted value by nearly 6 to 8 orders of magnitude. This was a completely unexpected result and the sharply decreasing trend of SF life-times of nuclei with $N>152$ was contrary to theoretical predictions. Hulet et al (1971) observed that even-even nuclei with $N=158$ are becoming catastrophically unstable towards spontaneous fission. This necessitated a thorough re-evaluation of the techniques of calculating the life-times of very heavy and superheavy nuclides. While it is recognised that the relatively long spontaneous fission half-life of 125 years for ${ }_{100}^{257} \mathrm{Fm}$ with 157 neutrons is due to the extra hindrance associated with SF of nuclei with an odd number of nucleons 
(Johansson 1959; Randrup et al 1973) the decrease in $t_{1 / 2}$ (SF) by a factor of nearly $10^{13}$ on adding just one more neutron to ${ }_{100}^{257} \mathrm{Fm}$ is indeed a dramatic effect.

This rather unexpected result, prompted a determined experimental effort not only to measure the SF lifetimes of many new heavy elment isotopes with neutron numbers in the vicinity of 158 , but also on other important fission characteristics such as mass distribution, total kinetic energy release etc. Some of the new and exciting results are discussed below.

Recently, the $t_{1 / 2}$ (SF) of ${ }_{98}^{256} \mathrm{Cf}$, which also has 158 neutrons as ${ }_{100}^{258} \mathrm{Fm}$, has been measured by Hoffman et al (1977) to be 12.3 minutes. This indicates a reduction by a factor of $1.4 \times 10^{-4}$ in half-life for addition of 2 neutrons to ${ }^{254} \mathrm{Cf}\left(T_{1 / 2}=60\right.$ days) compared to the reduction factor of $1.9 \times 10^{-3}$ in the case of ${ }_{98}^{252} \mathrm{Cf}$ to ${ }_{98}^{254} \mathrm{Cf}$. Although the half-life reduction for 2 neutrons between ${ }_{98}^{254} \mathrm{Cf}$ to ${ }_{98}^{256} \mathrm{Cf}$ is one order of magnitude larger than between ${ }_{98}^{252} \mathrm{Cf}$ and ${ }_{98}^{254} \mathrm{Cf}$, a 'disaster' for 158 neutrons appears to have been averted. Among the trans-fermium isotopes, with odd number of nucleons, ${ }_{101}^{259} \mathrm{Md}$ is again of special interest in that it also has 158 neutrons like ${ }_{100}^{258} \mathrm{Fm}$ but the odd nucleon hindrance effect referred to above is about $10 \%$ compared to ${ }_{100}^{258} \mathrm{Fm}$ making the $t_{1 / 2}(\mathrm{sF})$ of ${ }_{101}^{259} \mathrm{Md}$ to be $95 \mathrm{~min}$ (Wild et al 1979). These recent observations, suggest the possibility that for the even-even trans-fermium isotopes, the second fission barrier (Clark 1971) is absent leading to extremely short $t_{1 / 2}$ (SP)

The measurement of spontaneous fission half-life of ${ }_{104}^{258} \mathrm{Fm}$ also had a profound impact on the discovery of ${ }_{100}^{259} \mathrm{Fm}$, a nuclide with 159 neutrons (Hoffman et al 1976). On the basis of SF decay systematics and the known $t_{1 / 2}(\mathrm{SF})$ of 125 years for ${ }_{100}^{257} \mathrm{Fm}$, the $t_{1 / 2}(\mathrm{SF})$ of ${ }_{100}^{239} \mathrm{Fm}$ was estimated to be in the range of $5 \mathrm{hr}$ to 7.5 years. A search for ${ }_{100}^{259} \mathrm{Fm}$ in underground nuclear tests, however, failed to give any evidence of the presence of this isotope (Hoffman 1976). The discovery of 380 microsecond for the $t_{1 / 2}(\mathrm{SF})$ of ${ }_{100}^{258} \mathrm{Fm}$ indicating the on-set of a possible 'disaster' in spontaneous fission half-lives of nuclei with $N>157$ promted a re-estimate of the $t_{1 / 2}$ (SF) of heavier trans-fermium isotopes. This led to the thinking that ${ }_{100}^{258} \mathrm{Fm}$ and ${ }_{100}^{259} \mathrm{Fm}$ should have about the same spontaneous fission half-lives except for the special hindrance associated with the odd neutron in ${ }_{100}^{259} \mathrm{Fm}$ and its $t_{1 / 2}$ (SF) might be only a few tenths of a second. This information was valuable in designing the right type of experiments for the discovery of ${ }_{100}^{259} \mathrm{Fm}$ by the reaction ${ }^{257} \mathrm{Fm}(t, p)$ ${ }^{269} \mathrm{Fm}$. Its $t_{1 / 2}(\mathrm{SF})$ was found to be $1.5 \mathrm{sec}$.

Let us now quickly turn our attention to the other interesting features of fission, viz. mass distribution and kinetic energy release in the trans-fermium region. All previous measurements of low energy fission have shown the familiar asymmetric mass division, and the linear dependence of the average total kinetic energy (TKE) on $Z^{2} / A^{1 / 3}$. This is true upto and including the isotope ${ }_{100}^{257} \mathrm{Fm}$. However, addition of one extra neutron to ${ }_{100}^{257} \mathrm{Fm}$ completely changes the picture. ${ }_{100}^{258} \mathrm{Fm}$ and ${ }_{100}^{259} \mathrm{Fm}$ show symmetric mass division and the TKE is about $40 \mathrm{MeV}$ higher than the expected value. These results are shown in figures 4 and 5 respectively. On the basis of this, one would predict increased symmetric fission and higher TKE for heavy nuclei with neutron number $N \geqslant 158$. Surprisingly, however, the available data on the spontaneous fission of ${ }_{98}^{256} \mathrm{Cf}(N=158)$ and ${ }^{262} 105(N=157)$, one of the heaviest nuclide studied, do not show either increased symmetric fission or higher TKE. There is a distinct preference for mass asymmetry and normal kinetic energy release. The recent data on the spontaneous fission properties of ${ }_{101}^{259} \mathrm{Md}(N=158)$ is again somewhat perplex- 


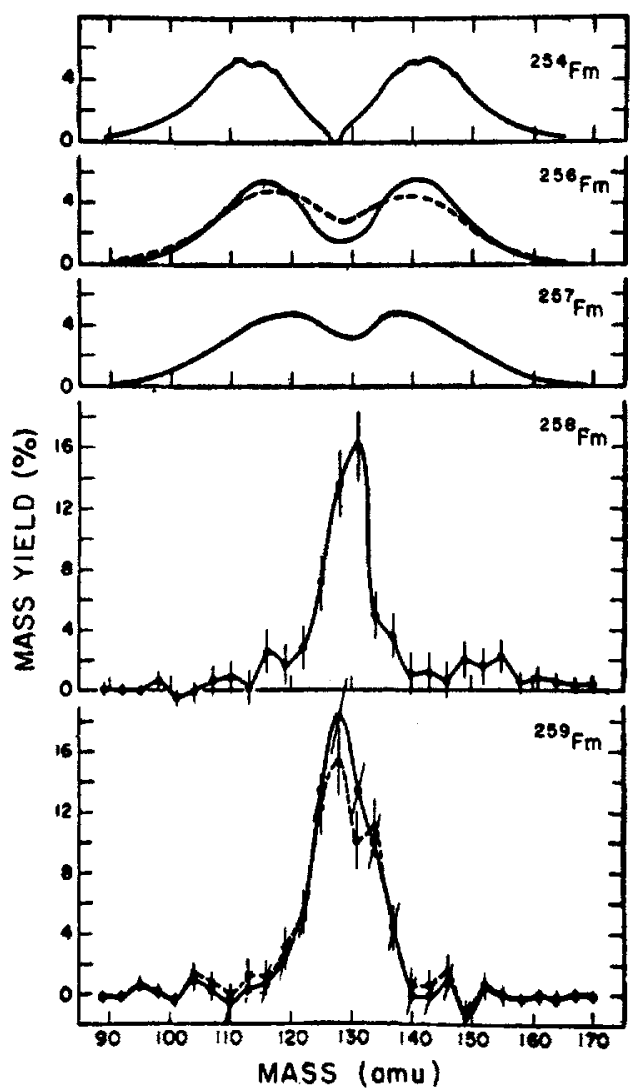

Figure 4. Trends in the mass distributions in the fission of fermium isotopes (Hoffman 1979).

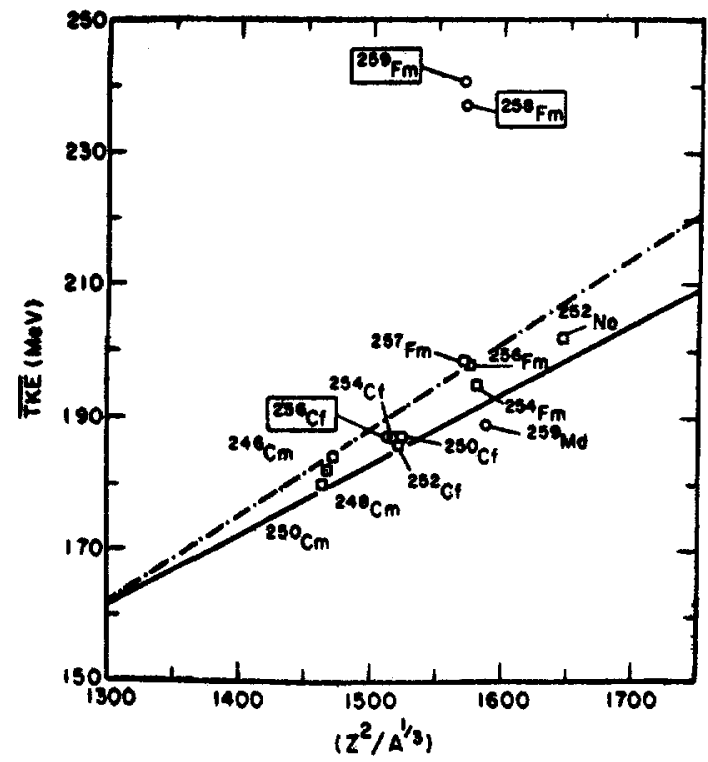

Figure 5. Trends in the total kinetic energy (TKE) release in the fission of very heavy actinides (Hoffman 1979). 
ing (Hulet et al 1979). The most interesting observation is that while sF of ${ }_{101}^{259} \mathrm{Md}$ and ${ }_{100}^{259} \mathrm{Fm}$ are highly symmetric like those of ${ }_{100}^{258} \mathrm{Fm}$, the total kinetic energy release is somewhat less than what is expected from the linear trend (see figure 5)-an observation which is inconsistent with current fission theories in which fragment shells govern the fission process. Perhaps, the odd proton in ${ }_{101}^{259} \mathrm{Md}$ may force a three-body breakup accounting for the low TKE leaving the nucleus to break into two fragments with $Z=50$. Other possibilities require storing of about $60 \mathrm{MeV}$ as internal energy for collective motion, internal rotation or internal heating.

Thus it would appear that ${ }_{100}^{257} \mathrm{Fm}(N=157)$ is in a sense 'unique' and in a 'transition' region. The addition of one extra neutron to ${ }_{100}^{257} \mathrm{Fm}$ brings about marked changes in the whole spectrum of fission properties of heavier nuclei. One key observation initially made possible by the innovative use of SSNTD-the determination of $t_{1 / 2}(\mathrm{SF})$ of ${ }_{100}^{258} \mathrm{Fm}$-has lead to many new and exciting results. It is clear, that further experimental efforts on the trans-fermium region are needed to check various theoretical approaches as well as to settle the issue of the suggested return to asymmetric mass division and lower TKEs.

\subsection{Life-times of compound nuclei}

Measurement of extremely short life-times of compound nuclei in the range $10^{-18}$ to $10^{-16} \mathrm{sec}$ through the ingeneous use of SSNTD in a technique called 'crystal blocking' is another landmark in the history of application of SSNTD to nuclear physics (Brown et al 1968). In this technique, the reaction products (excited compound nuclei with short life-times) are produced in thin single crystals and the probability of escape of their fission fragments is measured along different crystallographic directions. This indicates the distance travelled by the fissioning nucleus in the crystal. From a knowledge of the recoil velocity of the compound nucleus and the distance travelled by it within the crystal (which is obtained from the blocking pattern of the emitted fragments) the life-times are evaluated. Figure 6 shows the experimental arrangement and the results of Brown et al (1968) on the measurement of life-time for the fission of ${ }^{288} \mathrm{U}$ by $12 \mathrm{MeV}$ protons. Single crystals of $\mathrm{UO}_{2}$ were used as the target. Lexan detector placed at a distance of $50 \mathrm{~cm}$ collected the fission fragments emitted along the
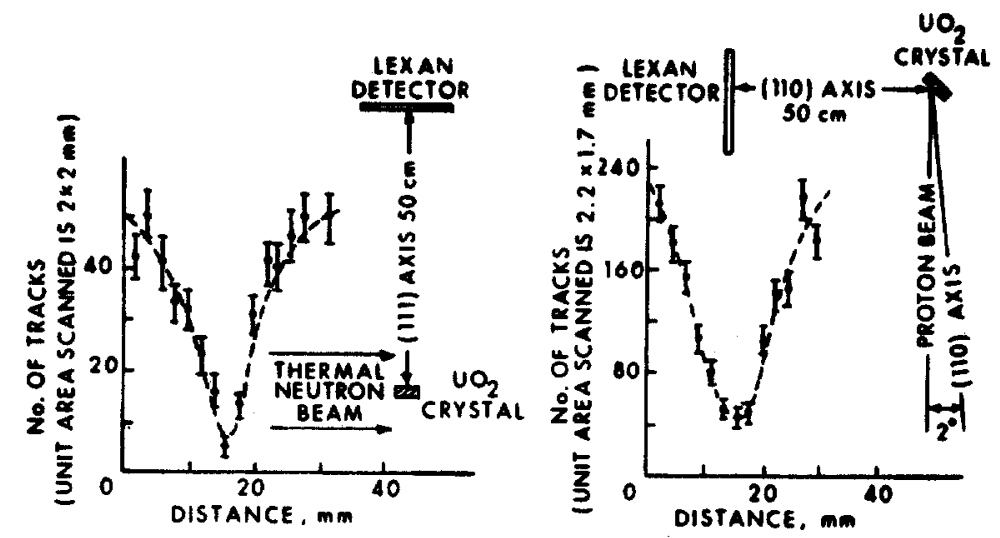

Figure 6. Extremely short life-times measurement by crystal blocking technique (Brown et al 1968). 
[110] axis. The figure represents the angular distribution of fission fragments (the blocking patterns) along the [110] axis in a thermal neutron and $12 \mathrm{MeV}$ proton irradiation. This showed that the total life time in the $12 \mathrm{MeV}$ proton fission of ${ }^{238} \mathrm{U}$ is less than $2 \times 10^{-17} \mathrm{sec}$. This technique will find important application in obtaining evidence for the formation of spontaneously fissioning superheavy elements with half-lives in the range of $10^{-14}-10^{-18}$ seconds in heavy ion-induced nuclear reactions (see $\S 3.5$ ).

\subsection{Fission cross-sections, excitation functions and angular distribution of fission fragments}

Voluminous data are available in the literature on fission cross-section and related measurements by using SSNTD. In all these studies, the extreme simplicity and sensitivity of SSNTD have been exploited. The work of Burnet et al (1964); on the helium ion induced fission of $\mathrm{Au}$ is a classic example of the use of SSNTD in low- $Z$ element fission studies. Here the insensitivity of mica to large doses of high energy alpha particles allowed extremely low fission cross-sections-as low as $10^{-35} \mathrm{~cm}^{2}$ - to be measured and the fission barrier for the ${ }^{201} \mathrm{Tl}$ compound nucleus to be estimated. In most of these studies, a target-detector assembly is used in a $2 \pi$ geometry. A typical $2 \pi$ geometry experimental set-up for the determination of fission cross-sections is shown in figure 7 in which a stack of thin electrodeposited targets in contact with the detector is assembled. Using this experimental set-up the $14 \mathrm{MeV}$ neutron fission cross-sections of a number of actinide elements were obtained in Trombay (Choudhuri et al 1979).

A very elegant use of plastic track detectors for studying the fission properties of low $Z$ elements was demonstrated by Raisbeck and Cobble (1967). These are extremely low fission cross-section processes and in order to get even the most qualitative information on such systems, it was necessary to develop detection techniques which are not only extremely sensitive but also highly discriminating. It was also necessary to use exceedingly pure targets with respect to heavy element contamination. The fragile nature of the targets (thin layer of oxides of thulium, lutetium and rhenium deposited on high purity silverfoils) and the requirement of intense doses of alpha particles ruled out the possibility of using a $2 \pi$ geometry set-up. The fission fragments recoiling out of the thin targets in the backward direction with respect to the incident beam of alpha particles were collected in a cylindrical lexan plastic detector.
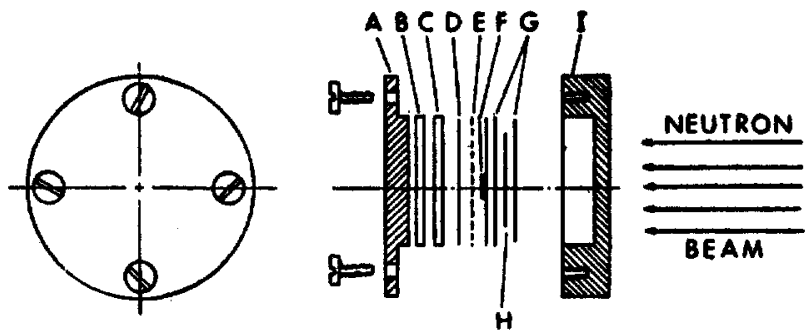

Figure 7. Schematic of irradiation assembly used for cross-section measurement: (A) perspex lid with screws, (B) and (C) perspex spacers, (D) and (G) Aluminium guard, (E) lexan detector, (F) target nuclide, (H) Al neutron monitor, and (I) perspex body (Choudhury et al 1979). 
This arrangement provided both the sensitivity and the necessary discrimination against non-fission spallation reactions. Using such a cylindrical backward recoil geometry they measured the fission excitation functions of ${ }_{69}^{169} \mathrm{Tm},{ }_{71}^{175} \mathrm{Lu}$ and ${ }^{185,}{ }_{75}^{187} \mathrm{Re}$ with $30-80 \mathrm{MeV}$ helium ions (figure 8).

In the case of low $Z$ elements neutron emission predominates over fission and the ratio of the fission cross-section to total reaction cross-section $\sigma_{f} / \sigma_{R}$ is nearly equal to the ratio of the fission width to neutron emission width $\Gamma_{f} / \Gamma_{n}$. For example, for lutetium excited with $40 \mathrm{MeV}$ helium ions, only one in $10^{8}$ nuclear interactions leads to a fission event. The fission excitation functions were analysed, using a statistical model expression suggested by Huizenga and Vandenbosch (1962) to extract the fission barriers, $E_{f}$.

$$
\begin{aligned}
\frac{\sigma_{f}}{\sigma_{R}} \approx & \frac{\Gamma_{f}}{\Gamma_{n}}=K_{0} \frac{a_{n}\left[2 a_{f}^{1 / 2}\left(E-E_{f}\right)^{1 / 2}-1\right]}{4 A^{2 / 3} a_{f}\left(E-B_{n}\right)} \times \\
& \exp \left[2 a_{f}^{1 / 2}\left(E-E_{f}\right)^{1 / 2}-2 a_{n}^{1 / 2}\left(E-B_{n}\right)^{1 / 2}\right],
\end{aligned}
$$

where $a_{n}$ and $a_{f}$ are the level density parameters for neutron emission and fission respectively, $E$ is the excitation energy, $E_{f}$ is the fission barrier, $B_{n}$ is the neutron binding energy, $A$ is the mass number of compound nucleus and $K_{0}$ is a constant. The calculated fission barriers are $22 \cdot 5,23 \cdot 6,27 \cdot 5$ and $28 \cdot 7 \mathrm{MeV}$ respectively for the compound nuclei ${ }^{189} \mathrm{Ir},{ }^{191} \mathrm{Ir},{ }^{179} \mathrm{Ta}$ and ${ }^{173} \mathrm{Lu}$. These data along with other data from the literature have been used to correlate the dependence of $\Gamma_{f} / \Gamma_{n}$ on the fissionability parameter $Z^{2} / A$ (normalised to an excitation energy of $40 \mathrm{MeV}$ ) and shown in figure 9 which shows a striking exponential relationship. A marked deviation starting at ${ }_{90}^{230} \mathrm{Th}$ (a compound nucelus formed in the reaction between ${ }_{2}^{4} \mathrm{He}$ and ${ }_{88}^{226} \mathrm{Ra}$ ) gives conclusive evidence for the transition from predominantly symmetric fission mode for

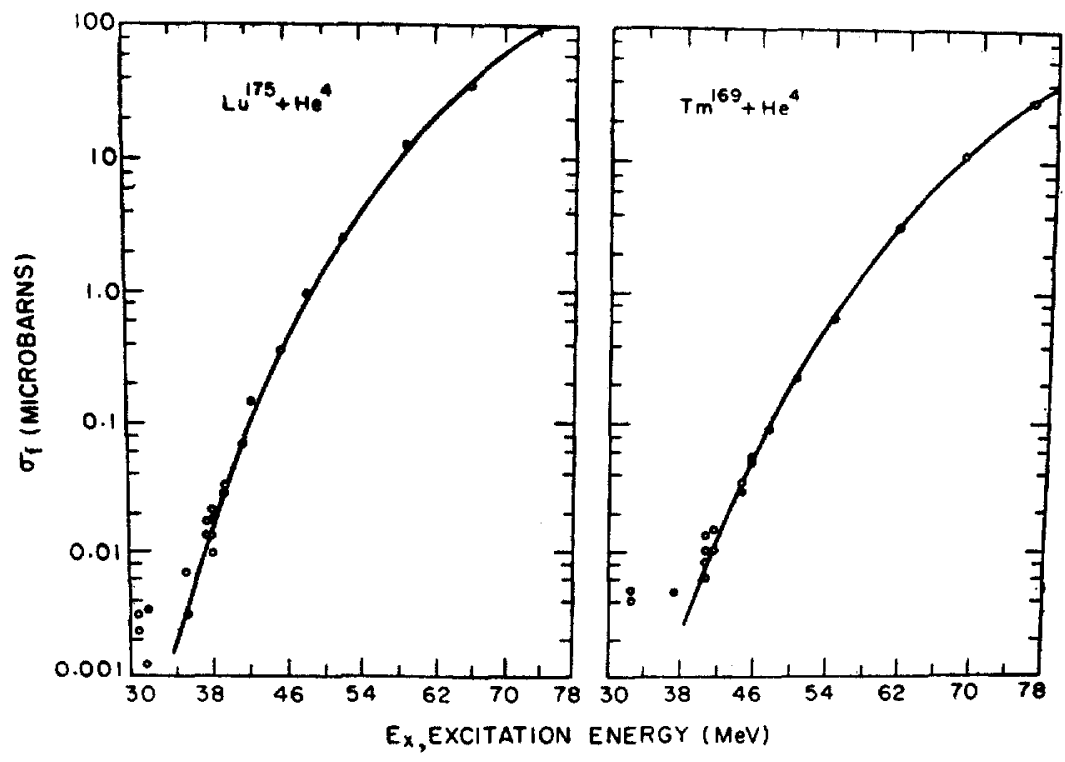

Figure 8. Helium-ion induced fission excitation functions of ${ }^{160} \mathrm{Tm}$ and ${ }^{176} \mathrm{Ln}$ (Raisbeck and Cobble 1967). 


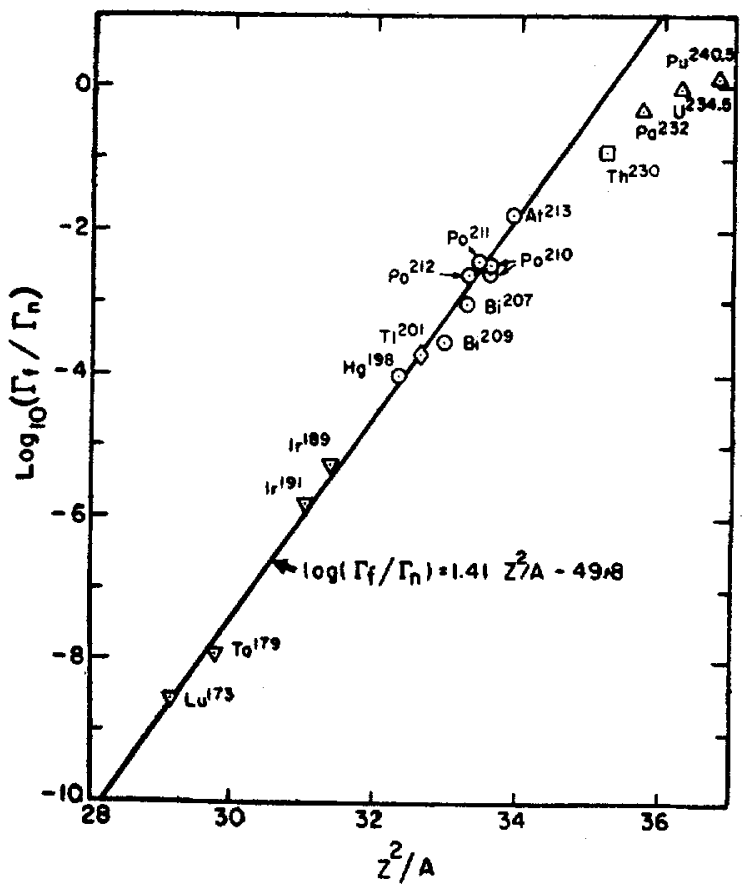

Figure 9. Correlation of $\Gamma_{f} / \Gamma_{n}$ with fissionability parameter $Z^{3} / A$ (Raisbeck and Cobble 1967).

low $Z$ elements $(Z<90)$ to assymetric fission mode in high $Z(Z>90)$ elements and corroborates the 'two-mode' fission hypothesis (Turkevich and Niday 1951). It is worth pointing out here that the fission of ${ }^{226} \mathrm{Ra}$ with ${ }^{4} \mathrm{He}$ ions (compound nucleus ${ }_{90}^{230} \mathrm{Th}$ ) gives a 'triple-humped' mass distribution with nearly equal contributions from both the symmetric and the asymmetric fission modes (Fairhall et al 1958).

We conclude this discussion by citing one example of the innovative use of SSNTD for the measurement of fission fragment angular distributions carried out at BARC (Chaudhuri et al 1979). Using a novel fission recoil chamber about the size of a ' grape fruit' evolved from considerations of neutron economy, it was possible to get the $14 \mathrm{MeV}$ neutron fission fragment angular distributions of five independently fissioning actinide nuclei at a time. The fragments were collected in cylindrical lexan detectors in a forward recoil geometry. The experimental set-up and the geometry are shown in figures 10 and 11 . Horizontal scans of the unfolded detector give the track density at a given angle of emission, $\theta$, of fragments with respect to the neutron beam. The working of the recoil chamber and the method of calculation was checked by observing isotropic distribution of fragments in the thermal neutron fission of ${ }^{235} \mathrm{U}$ and ${ }^{239} \mathrm{Pu}$ (figure 12). From the measured track density, $T d$, and from a knowledge of the radius of the cylindrical detector, $R$, and the angle, $\theta$, the angular distributions were calculated using the expression

$$
\left(\frac{d \sigma}{d \Omega}\right)_{\theta}=\frac{\text { constant } \times R^{2} \times T d}{\sin ^{3} \theta}
$$

where the constant depends on the experimental parameters such as the neutron 


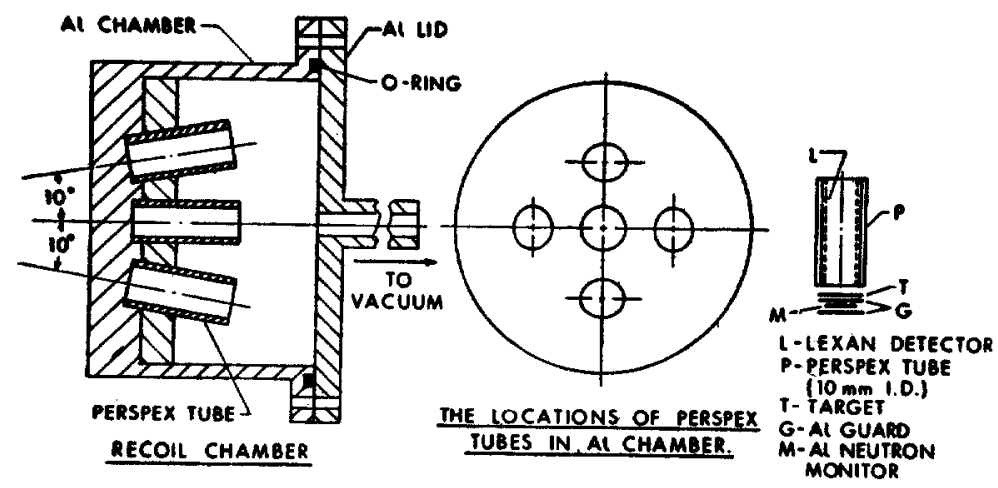

Figure 10. Schematic diagram of the recoil chamber used in angular distribution measurements (Choudhury et al 1979).
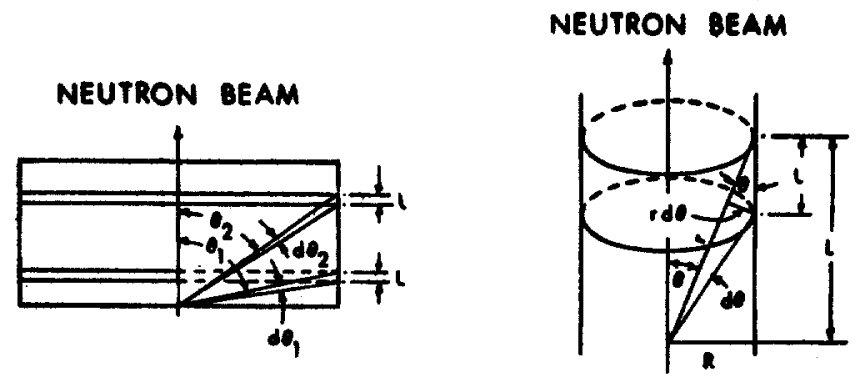

Figure 11. Schematic diagram showing the track registration geometry used for angular distribution measurements (Choudhury et al 1979).

flux, time of irradiation, number of target atoms etc. The expected trend of decrease of the anisotropy in the fragment angular distribution with increasing $Z^{2} / A$ of the compound nucleus was observed. From an analysis of the data, the third chance fission thresholds $\left(n, 2 n^{\prime} f\right)$ for the fission of ${ }^{291} \mathrm{~Pa}$ and ${ }^{241} \mathrm{Am}$ were evaluated to be $13 \cdot 2$ and $11 \cdot 1 \mathrm{MeV}$ respectively.

\subsection{Fission isomers}

We now turn our attention to another major area of fission studies namely fission isomers and the double-humped fission barrier which has revolutionised our understanding of the fission process in the last two decades and where SSNTD has played a key role in collecting valuable experimental information. In 1962, at Dubna, USSR, Polikanov et al reported the accidental discovery of a 14 millisecond spontaneous fission isotope ${ }_{95}^{242} \mathrm{Am}$ in a reaction involving accelerated ${ }^{22} \mathrm{Ne}$ ion with ${ }^{238} \mathrm{U}$. This was a startling result in that the ground state spontaneous fission half-life of ${ }_{95}^{242} \mathrm{Am}$ estimated from spontaneous fission systematics was about $10^{10}$ times longer. Subsequent theoretical and experimental research led to the identification of the 14 millisecond spontaneous fission activity as being due to a metastable state of ${ }^{242} \mathrm{Am}$. This new state of metastability was termed as 'shape isomerism ' to distinguish it from the familiar spin isomerism in the forbidden gamma transitions and the idea of the 'double-humped fission barrier' was born (Clark 1971). 

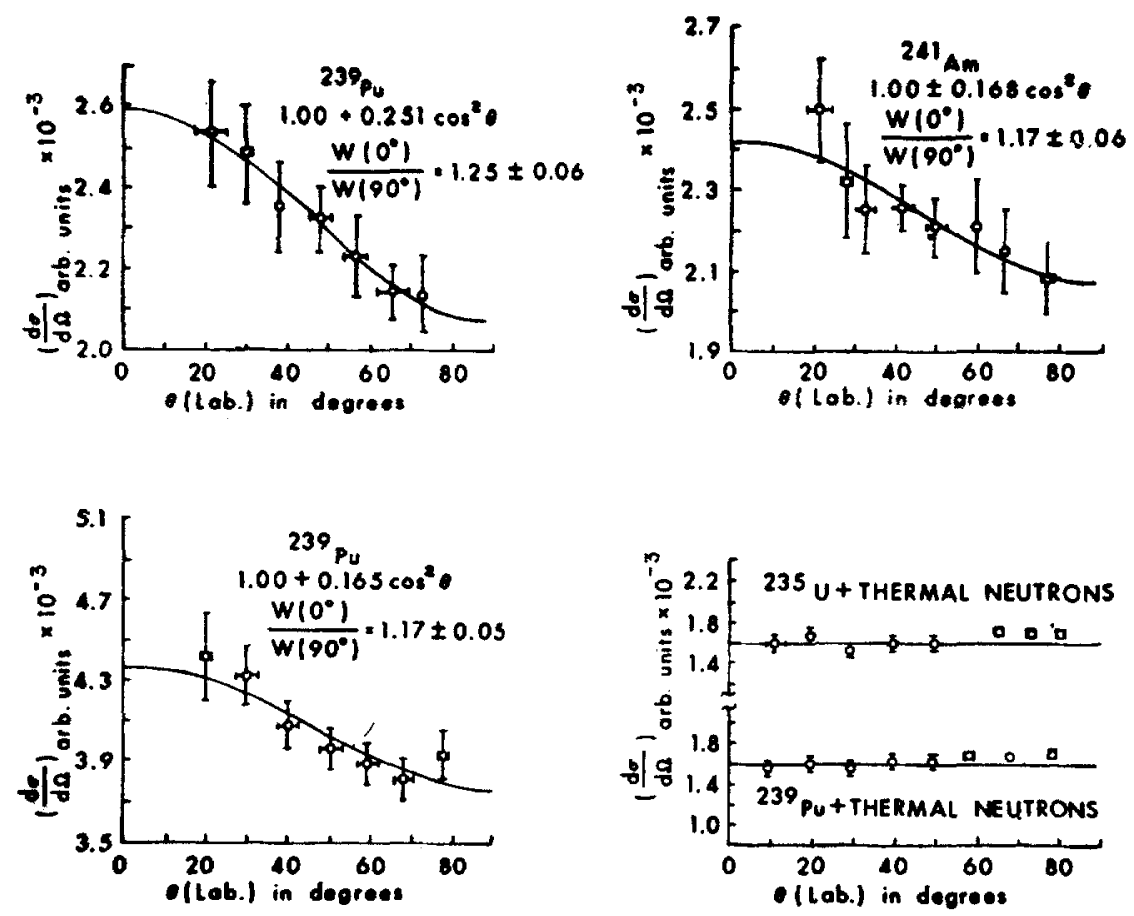

Figure 12. Experimental fission fragment angular distributions in the thermal and $14 \mathrm{MeV}$ neutron induced fission of actinide isotopes (Choudhury et al 1979).

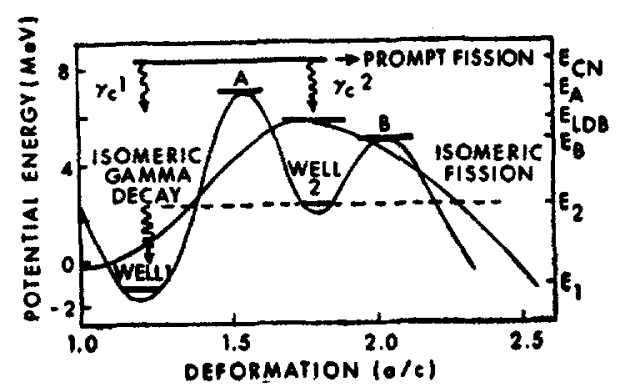

Figure 13. The double-humped fission barrier (Clark 1971).

In order to appreciate the significant role the SSNTDs have played in this area it is worthwhile considering the phenomenon in some detail. Let us do it with the help of figure 13 taken from Clark (1971). In the conventional ground state spontaneous fission, the ground state nucleus tunnels through the entire potential barrier (the singlehumped barrier based on liquid drop model shown in the figure) and consequently has long spontaneous fission life-times. This is equivalent to having the nucleus trapped in well 1 with a ground state energy of $E_{1}$. On the other hand, if a nucleus is trapped in well 2 with an excitation energy $E_{2}$, then, its decay is hindered by both the inner and the outer potential barriers. In other words it is in an isomeric or metastable state. Decay to the right (through the smaller barrier) is by isomeric fission and decay to the left by gamma emission. $E_{\mathrm{A}}, E_{\mathrm{B}}$ and $E_{\mathrm{LDB}}$ are the heights of the 
inner barrier $A$, outer barrier $B$ and the liquid drop barrier respectively. A nucleus excited to an excitation energy $E_{\mathrm{CN}}$ can de-excite either by prompt fission or by gamma decay into the wells 1 and 2.The enormous enhancement of the fission rate of ${ }^{242 m} \mathrm{Am}$ can now be understood by assuming it as an isomeric state trapped in well 2 where the probability of tunnelling through the 2 nd barrier B is much greater compared to the ground state nucleus in well 1.

The main category of experimental support for the existence of the double-humped fission barrier comes from a study of fission isomers. Another piece of experimental evidence is the occurrence of structures in the sub-threshold fission excitation functions in neutron or deuteron-induced reactions of actinide nuclei. Several experimental approaches have been evolved to identify new cases of fission isomers in order to establish the generality of the phenomenon. In these experiments, the rotating drum and the moving belt methods described in $\S 3 \cdot 1$ have been extensively used in conjunction with mica, makrafol and lexan detectors. The mechanical constraints limit the usefulness of these techniques to half-lives greater than about one millisecond.

The identification of fission isomers with much shorter half-lives (in the nanosecond to microsecond region) calls for greater ingenuity on the part of the experimenter-the serious problem being the need to discriminate against the predominant prompt fission process. Using large area plastic track detectors in a geometrical arrangement that shielded prompt fission but recorded delayed fission from nuclei in flight, Lark et al (1969) in Copenhagen were able to observe about ten new cases of fission isomers with half-lives ranging from 5 nanosec to 1.5 micro seconds. The experimental arrangement is given in figure 14. The half-lives were calculated from the estimated recoil velocity of the nuclei in flight and the density of fission tracks as a function of distance from the target. A slightly modified approach has been employed by Mehta and coworkers at BARC to measure the isomeric fission cross-section for the ${ }^{238} \mathrm{U}\left(n, n^{\prime}\right){ }^{238 m U} \mathrm{U}$ reaction in the $14 \mathrm{MeV}$ neutron induced fission of ${ }^{238} \mathrm{U}$ (Chaterjee et al 1981). An annular plastic track detector (makrofol) in a recoil geometry was used to register delayed fission events. The plastic detector was kept in the same plane as the target so that it does not register prompt fission events. A catcher foil was kept at a distance of $1.5 \mathrm{~cm}$ from the target to stop the recoiling uranium nuclei and to improve the geometrical efficiency of the detector.

As already pointed out, experimental evidence for the double-humped fission barrier comes from the existence of fission isomers as well as from the occurrence of structures in the sub-threshold fission excitation functions. In general, it is observed

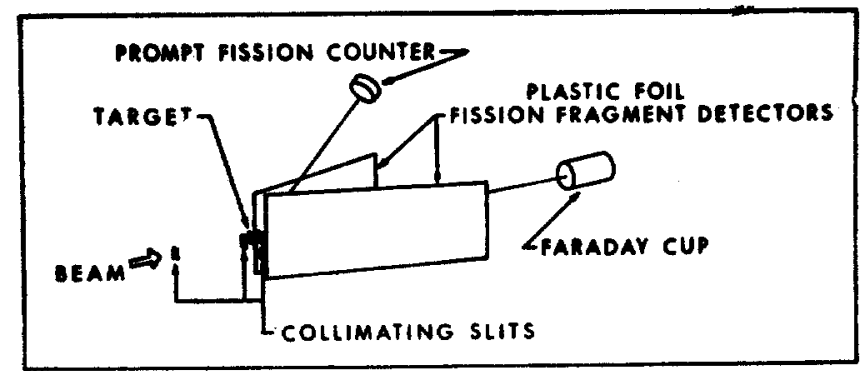

Figure 14. Experimental arrangement for the measurement of half-lives of fission isomers in the nano-second region (Lark et al 1969). 
that for higher actinides the 2nd barrier is smaller than the 1st barrier (and even disappears with increasing $Z$ ) while for the lighter actinides such as thorium, the reverse seems to be the case making gamma decay heavily favoured over fission. This effect probably accounts for the absence of many fissioning isomers in this region. The structures seen in the sub-threshold fission excitation functions of ${ }^{230} \mathrm{Th}$ etc. are correlated with a vibrational resonance in the 2 nd well.

A critical and comprehensive account of the information available on doublehumped fission barrier that can be deduced from the vast amount of experimental work is given by Bjornholm and Lynn (1980). As of today 45 fission isomers with half-lives in the range of less than 5 picoseconds to 14 milliseconds have been identified in the U-BK region. These are listed in table 2. SSNTDs have played a significant role in the discovery of many of these isomers and have thus contributed to the present state of our understanding of the double humped fission barrier.

\subsection{Search for superheavy elements}

The existence of an island of stable elements beyond the present periodic table has been predicted by theoretical extrapolations of the nuclear properties (Seaborg 1969;

Table 2. Occurrence and half-lives of fission isomers in the uranium-berkelium region*

\begin{tabular}{|c|c|c|c|c|c|}
\hline Nucleus & & $t_{1 / 2}$ & Nucleus & & $t_{1 / 3}$ \\
\hline${ }^{288} \mathrm{U}$ & 125 & $\pm 15 \mathrm{nsec}^{(a)}$ & ${ }^{237} \mathrm{Am}$ & 5 & 上 $2 \mathrm{nsec}$ \\
\hline${ }^{288} U$ & 195 & $\begin{array}{l} \pm 30 \mathrm{nsec}^{(a)} \\
>1 \mathrm{nsec}\end{array}$ & $\begin{array}{l}{ }^{288} \mathrm{Am} \\
{ }^{239} \mathrm{Am}\end{array}$ & $\begin{array}{r}35 \\
163\end{array}$ & $\begin{array}{l} \pm 4 \mu \mathrm{sec} \\
\pm 12 \mathrm{nsec}\end{array}$ \\
\hline${ }^{233} \mathrm{~Np}$ & 40 & $\pm 12 \mathrm{nsec}^{(a)}$ & ${ }^{940} \mathrm{Am}$ & 0.91 & $\pm 0.07 \mathrm{msec}$ \\
\hline${ }^{286} \mathrm{Pu}$ & 30 & $\pm 5 \mathrm{nsec}$ & ${ }^{241} \mathrm{Am}$ & $1 \cdot 5$ & $\pm 0.6 \mu \mathrm{sec}$ \\
\hline${ }^{286} \mathrm{Pu}$ & $\begin{array}{l}40 \\
34\end{array}$ & $\begin{array}{l} \pm 15 \text { psec } \\
\pm \quad 8 \mathrm{nsec}\end{array}$ & ${ }^{242} \mathrm{Am}$ & $\begin{array}{l}14 \\
5 \cdot 5\end{array}$ & $\begin{array}{l} \pm \quad 0.7 \mathrm{msec} \\
\pm \quad 0.5 \mu \mathrm{sec}\end{array}$ \\
\hline${ }^{287} \mathrm{Pu}$ & $\begin{array}{l}110 \\
1 \cdot 1\end{array}$ & $\begin{array}{l} \pm 12 \mathrm{nsec} \\
\pm 0.08 \mu \mathrm{sec}\end{array}$ & $\begin{array}{l}{ }^{244} \mathrm{Am} \\
{ }^{245} \mathrm{Am}\end{array}$ & $\begin{array}{c}1 \cdot 0 \\
640\end{array}$ & $\begin{array}{l} \pm 0.15 \mathrm{msec} \\
\pm 60 \mathrm{nsec}\end{array}$ \\
\hline${ }^{288} \mathrm{Pu}$ & $\begin{array}{l}0.5 \\
6.0\end{array}$ & $\begin{array}{l} \pm 0.2 \mathrm{nsec} \\
\pm 1.5 \mathrm{nsec}\end{array}$ & ${ }^{{ }^{846} \mathrm{Am}}$ & $\begin{array}{l}73 \\
10\end{array}$ & $\begin{array}{l} \pm 10 \mu \mathrm{sec} \\
\pm 2 \mathrm{psec}\end{array}$ \\
\hline${ }^{23} \mathrm{Pu}$ & $\begin{array}{l}8 \cdot 1 \\
3 \cdot 0\end{array}$ & $\begin{array}{l} \pm 0.8 \mu \mathrm{sec} \\
\pm 2 \mathrm{nsec}\end{array}$ & ${ }^{241} \mathrm{Cm}$ & $\begin{array}{l}55 \\
15\end{array}$ & $\begin{array}{l} \pm 5 \text { nsec } \\
\pm \quad 1 \text { nsec }\end{array}$ \\
\hline${ }^{240} \mathrm{Pu}$ & $3 \cdot 8$ & $\pm 0.3 \mathrm{nsec}$ & ${ }^{248} \mathrm{Cm}$ & 40 & \pm 15 psec \\
\hline${ }^{241} \mathrm{Pu}$ & 24 & $\pm 1 \mu \mathrm{sec}$ & ${ }^{243} \mathrm{Cm}$ & $\begin{array}{r}180 \\
42\end{array}$ & $\begin{array}{l} \pm 70 \mathrm{nsec} \\
\pm 6 \mathrm{nsec}\end{array}$ \\
\hline${ }^{242} \mathrm{Pu}$ & $\begin{array}{l}30 \\
3.6\end{array}$ & $\begin{array}{l} \pm 5 \mathrm{nsec} \\
\pm 0.6 \mathrm{nsec}\end{array}$ & ${ }^{244} \mathrm{Cm}$ & & $\begin{array}{l}<5 \mathrm{psec} \\
>100 \mathrm{nsec}\end{array}$ \\
\hline & 50 & I: 30 nsec & ${ }^{245} \mathrm{Cm}$ & 13 & $\pm 2 \mathrm{nsec}$ \\
\hline${ }^{248} \mathrm{Pu}$ & 60 & $\pm 15 \mathrm{nsec}$ & ${ }^{249} \mathrm{Bk}$ & 600 & $\pm 100 \mathrm{nsec}$ \\
\hline${ }^{244} \mathrm{Pu}$ & 0.4 & $\pm \quad 0.1 \mathrm{nsec}$ & & $9 \cdot 5$ & $\pm 2 \mathrm{nsec}$ \\
\hline${ }^{245} \mathrm{Pu}$ & 90 & \pm 30 nsec & $\begin{array}{c}{ }^{243} \mathrm{Bk} \\
{ }^{244} \mathrm{Bk} \\
{ }^{245} \mathrm{Bk}\end{array}$ & $\begin{array}{r}5 \\
820 \\
2\end{array}$ & $\begin{array}{l} \pm 2 \mathrm{nsec} \\
\pm 60 \mathrm{nsec} \\
\pm 1 \mathrm{nsec}\end{array}$ \\
\hline
\end{tabular}

*Taken from Bjornholm and Lynn (1980).

In a number of nuclei 2 decay periods are identified. The second one is presumably due to an excited state in the second well.

(a) gamma decay to the left competes with fission to the right of the second well. 
Otto et al 1978). During the past 10-12 years extensive search for superheavy elements (SHE) both in nature and in the laboratory viz. heavy ion induced nuclear reactions has been made but without much success. In these searches, SSNTDs have played a significant role and they will continue to do so in future also. We outline some of the techniques used in this continuing search and the current thinking on where and how to look for SHE in nature and in the laboratory. Most of the information is based on the work of Seaborg, Flerov and Hermann and their colleagues in the USA, USSR and FRG respectively (Otto et al 1978; Flerov et al 1978; Hermann 1979).

The search for sHe in nature are based on two assumptions: (a) they decay either by spontaneous fission or are in secular equilibrium with a descendent which decay by $\mathrm{SF}$, (b) they follow the lower homologues both in geochemical fractionation and in industrial processes. A suggestion has been made to look for eka-elements of easily volatile elements in nature (Nurmia 1974). The exciting possibility exists that SHE are produced in supernova explosion or other astrophysical processes and reach the earth's atmosphere or deep-sea sediments as cosmic fall outs (Nurmia 1974).

Let us now consider the possible modes of formation of SHE in the laboratory through heavy ion reactions. Here, three principal mechanisms are considered. The first one is exchange of a few nucleons between the two colliding nuclei in a rather distant collision called quasi-elastic transfer. If the collisions are closer, then two new possibilities arise, viz. for complete fusion or for the nuclei to stick together for about $10^{-21} \mathrm{sec}$ to form a composite system in which the entire kinetic energy of the projectile is transferred into internal excitation or rotation. This process is called strongly damped or deep inelastic collision. During such a process a substantial number of nucleons from the projectile can be transferred into the target nuclei. In complete fusion, which is favoured in reactions with light heavy ions such as $\mathrm{C}, \mathrm{O}, \mathrm{Ar}$ etc., the compound nucleus will be highly excited and will decay by evaporation of several nucleons, alpha particles and gamma rays and the residual nucleus may undergo fission. In deep inelastic collisions, the system decays by emission of neutrons, protons, gamma rays or by fission. It is this process which is likely to lead to the formation of SHE. Because of the need for transferring a large number of nucleons to reach the SHE regions, reactions involving very heavy projectiles such as ${ }^{197} \mathrm{Au},{ }^{208} \mathrm{~Pb}$, ${ }^{238} \mathrm{U}$, etc. with heavy target nuclei such as ${ }^{238} \mathrm{U},{ }^{248} \mathrm{Cm},{ }^{249} \mathrm{Cf},{ }^{254} \mathrm{Fm}$ are being considered. Table 3 gives a summary of the attempts made so far (1979) to synthesise SHE by complete fusion reactions.

We now consider the various techniques that are employed for the detection of SHE. The spontaneous fission decay with a wide range of half-lives and the large predicted kinetic energy releases essentially form the basis for their detection. In view of the extremely small formation cross-sections (of the order of nanobarns or less) the detection system should be extremely sensitive. The complex nature of the reaction products demands high specificity in addition to sensitivity. The similarity of predicted chemical properties of SHE and their lower homologues also come in handy in selecting natural samples and form the basis of devising chemical separation schemes for isolating SHE fractions from targets irradiated with heavy ions (Seaborg 1969). A general survey of techniques available to detect SHE in heavy ion induced reactions is given in table 4. The measurable half-lives range from a few seconds to about $10^{-18} \mathrm{sec}$. Of particular interest to our discussion are the mechanical transport systems like rotating drums, moving belt, etc. which 
Table 3. Attempts to synthesise sHe by fusion reactions*.

\begin{tabular}{|c|c|c|}
\hline System & Compound nucleus & $\begin{array}{l}\text { Upper limit for } \\
\text { production cross- } \\
\text { section }\left(\mathrm{cm}^{2}\right)\end{array}$ \\
\hline${ }_{90}^{238} \mathrm{Th}+{ }_{90}^{18} \mathrm{Ca}$ & ${ }^{280} 110^{170}$ & $3 \times 10^{-85}$ \\
\hline${ }_{01}^{881 P a}+{ }_{20}^{48} \mathrm{Ca}$ & ${ }^{979} 111^{108}$ & $4 \times 10^{-85}$ \\
\hline${ }_{92}^{233} \mathrm{U}+{ }_{20}^{48} \mathrm{Ca}$ & ${ }^{281} 112^{16 \theta}$ & $7 \times 10^{-35}$ \\
\hline${ }_{96}^{248} \mathrm{Cm}+{ }_{18}^{40} \mathrm{Ar}$ & ${ }^{288} 114^{174}$ & $2 \times 10^{-32}$ \\
\hline${ }_{94}^{242} \mathrm{Pu}+{ }_{20}^{48} \mathrm{Ca}$ & ${ }^{290} 114^{178}$ & $1 \times 10^{-35}$ \\
\hline${ }_{96}^{2439} \mathrm{Am}+{ }_{20}^{48} \mathrm{Ca}$ & ${ }^{201} 115^{170}$ & $2 \times 10^{-85}$ \\
\hline${ }_{96}^{246} \mathrm{Cm}+{ }_{80}^{88} \mathrm{Ca}$ & ${ }^{894} 116^{178}$ & $2 \times 10^{-95}$ \\
\hline${ }_{86}^{248} \mathrm{Cm}+{ }_{20}^{18} \mathrm{Ca}$ & ${ }^{296} 116^{180}$ & 一 \\
\hline${ }_{82}^{208} \mathrm{~Pb}+{ }_{86}^{84} \mathrm{Kr}$ & ${ }^{892} 118^{174}$ & $1 \times 10^{-80}$ \\
\hline${ }_{82}^{209} \mathrm{~Pb}+{ }_{86}^{86} \mathrm{Kr}$ & $901118^{176}$ & $\begin{array}{l}6 \times 10^{-35} \\
1.5 \times 10^{-30}\end{array}$ \\
\hline${ }_{98}^{298} \mathrm{U}+{ }_{977}^{59} \mathrm{Co}$ & 897119178 & $4 \times 10^{-33}$ \\
\hline${ }_{92}^{298} \mathrm{U}+{ }_{28}^{(80)} \mathrm{Ni}$ & ${ }^{208} 120^{178}$ & $2 \times 10^{-83}$ \\
\hline${ }_{92}^{288} \mathrm{U}+{ }_{29}^{(68)} \mathrm{Cu}$ & ${ }^{303} 121^{182}$ & $8 \times 10^{-33}$ \\
\hline${ }_{92}^{298} \mathrm{U}+{ }_{20}^{65} \mathrm{Cu}$ & & $\begin{array}{l}2 \times 10^{-33} \\
4 \times 10^{-34}\end{array}$ \\
\hline${ }_{80}^{2832} \mathrm{Th}+{ }_{82}^{66 \mathrm{Ge}}$ & ${ }^{808} 122^{186}$ & $1 \times 10^{-34}$ \\
\hline${ }_{68}^{186} \mathrm{Xe}+{ }_{68}^{170} \mathrm{Er}$ & ${ }^{806} 122^{194}$ & $1.5 \times 10^{-83}$ \\
\hline${ }_{92}^{238} \mathrm{U}+{ }_{39}^{78} \mathrm{Ge}$ & ${ }^{314} 124^{190}$ & $1 \times 10^{-84}$ \\
\hline${ }_{95}^{243} \mathrm{Am}+{ }_{30}^{89} \mathrm{Zn}$ & ${ }^{311} 125^{188}$ & $5 \times 10^{-32}$ \\
\hline${ }_{90}^{882} \mathrm{Th}+{ }_{36}^{84} \mathrm{Kr}$ & ${ }^{819} 126^{100}$ & $5 \times 10^{-3 a}$ \\
\hline${ }_{82}^{288} \mathrm{U}+{ }_{36}^{84} \mathrm{Kr}$ & ${ }^{329} 128^{104}$ & $8 \times 10^{-89}$ \\
\hline
\end{tabular}

*Taken from Hermann (1979).

are applicable to species with millisecond half-lives and the crystal blocking technique which are applicable to the extreme region of $10^{-14}-10^{-18} \mathrm{sec}$.

Hundreds of natural samples including lead from old cathedrals, manganese nodules from the ocean floor, water from hot springs, meteorites and lunar samples have been investigated for possible evidence for SHE based on direct or indirect detection of fission events. Fission tracks are looked for in glass, mica or plastics in contact with the sample. Neutrons emitted in the fission process are also looked for. Assuming a half-life of $10^{9}$ years, these detection techniques have a sensitivity of 
Table 4. Techniques for detection of sHE produced in heavy ion reactions

\begin{tabular}{|c|c|c|c|}
\hline Technique & $\begin{array}{l}\text { Approximate } \\
\text { range of half-lives } \\
\text { (seconds) }\end{array}$ & $\begin{array}{c}\text { Cross-section } \\
\operatorname{limit}_{\left(\mathrm{cm}^{2}\right)}\end{array}$ & Remarks \\
\hline Chemical separation & 1 to $10^{7}$ & $10^{-80}$ & $\begin{array}{l}\text { Combined with fission frag- } \\
\text { ment detection. } \\
\text { Corresponds to one atom } \\
\text { of sHE per } 10^{12} \text { reactions. }\end{array}$ \\
\hline Gas jet system & 0.1 & - & $\begin{array}{l}\text { Activity is transported from } \\
\text { production site to detector. }\end{array}$ \\
\hline $\begin{array}{l}\text { Mechanical transport } \\
\text { Drums and Tapes }\end{array}$ & $10^{-3}-10^{4}$ & $10^{-85}$ & \\
\hline $\begin{array}{l}\text { Magnetic and electro- } \\
\text { static detection }\end{array}$ & $10^{-6}-10^{8}$ & $10^{-34}$ & \\
\hline $\begin{array}{l}\text { Time of flight and } \\
\text { energy loss } \\
\text { TOF-dE/dX-E }\end{array}$ & $10^{-8}-10^{-8}$ & $10^{-28}$ & \\
\hline Decay in flight & $10^{-10}-10^{-8}$ & $10^{-93}$ & $\begin{array}{l}\text { Using metal absorber foils } \\
\text { and observing fission frag- } \\
\text { ments perpendicular to the } \\
\text { flight path, half-lives of } \\
10^{-11} \text { sec can be detected. }\end{array}$ \\
\hline Crystal blocking & $10^{-14}-10^{-18}$ & $10^{-30}$ & \\
\hline
\end{tabular}

$10^{-12}$ to $10^{-14} \mathrm{~g}$ of SHE per gram of the sample. An exhaustive list of searches for SHE with track detectors is given by Fleischer et al (1975). While all these searches for SHE in nature have given negative results, there are two recently identified natural sources which deserve attention (Hermann 1979). One is the hot spring water from the Cheleken peninsula in the Caspian sea (Flerov et al 1978), and the other the carbonaceous chondrite meteorite Allende. The hot spring water from Cheleken peninsula is rich in volatile elements and is supposed to carry material escaping from great depths in the earth's mantle. Weak spontaneous fission activities have been detected by processing about 2000 cubic metres of water through ion exchange elution and subsequent chemical separations.

The 'superheavy element connection' of several carbonaceous chondrite meteorites comes from the fact they they contain an excess of neutron rich xenon isotopes of fission origin (e.g. ${ }^{136} \mathrm{Xe}$ ) as well as volatile elements such as thallium, bismuth and indium (Anders and Heyman 1969; Anders and Larimer 1972). They also contain neutron deficient xenon isotopes giving anomalous ${ }^{136} \mathrm{Xe} /{ }^{132} \mathrm{Xe}$ ratios. From a parallelism in the condensation history of fissiogenic xenon and of volatile elements it appears that the neutron-rich xenon isotopes originate from the spontaneous fission of a volatile superheavy element eka-bismuth (115), eka-lead (114) or eka-thalium (113) (Anders et al 1975). Flerov et al (1977) and Popeko and Ter-akopyan (1979) have observed weak spontaneous fission activity of the order of one event per month per kilogram in meteorite Allende. Using an evaporationcondensation technique attempts are being made to concentrate the possible superheavy fraction from Allende (Zvara et al 1977).

From the foregoing discussion, it is clear that the searches for sHE both in nature and in the laboratory are continuing but so far she has eluded detection. Current 
hopes of synthesising superheavy elements are pinned down on the reaction between two colliding uranium nuclei at the Darmstadt unILAC accelerator (Hermann 1979). With the versatility of SSNTDs coupled with the current developments and refinements in the methodology of detection systems it is hoped that track detectors will play an important role in the eventual discovery of superheavy elements.

\subsection{Absolute fission-yield measurements}

So far, we have been discussing those areas of fission physics and chemistry where the direct or indirect use of solid state nuclear track detectors have contributed immensely to the growth of fundamental knowledge. We now cite one area of fission studies where the use of these detectors has yielded results of applied interest namely, absolute fission yield measurements. This is particularly relevant in the present context when the relevance of basic research is often debated upon.

Accurate fission product nuclear data such as fission yields, cross-sections, decay schemes etc. are required to resolve a number of problems associated with the design and operation of thermal and fast reactors as well as for other applications such as nuclear safeguards. Their importance can be judged from the fact that international conferences on fission product nuclear data are periodically being organised by the IAEA. The current trend with respect to fission yield measurements is towards measurements at known neutron spectrum and on an absolute basis. For thermal reactors, the fission product yields of ${ }^{239} \mathrm{Pu}$ and ${ }^{241} \mathrm{Pu}$ are becoming increasingly important, but the yields are more uncertain than those of ${ }^{235} \mathrm{U}$. Information for calculating decay heat data from fission products following a potential loss of coolant accident are urgently needed for all reactor systems for their safer design. Thes calculations (Baumung 1977) require the independent and fractional chain yields, beta and gamma energies, half-lives etc. of more than 400 short-lived fission products. At present these are estimated from theory.

Measurement of fission product yields require two basic input data: (a) the total number of fissions occurring in the target and (b) the number of fission product atoms formed. The total number of fissions is related to, $n$, the number of atoms undergoing fissions, $\sigma$, the fission cross-section $\left(\mathrm{cm}^{2}\right), \phi$, the neutron flux $\left(\mathrm{cm}^{-2} \mathrm{sec}^{-1}\right)$ and the irradiation time, $t$ (sec.) by the equation

$$
F=n \sigma \phi t
$$

This crucial quantity is generally measured by (i) isotope dilution mass spectrometry, (ii) measuring the neutron flux in the irradiation environment, and (iii) using a fission chamber. The problems and inaccuracies associated with these methods have been reviewed by Lammer and Eder (1973) and by Ramaswami et al (1979).

The number of fission product atoms is determined by general radiometric methods (beta or gamma counting) or by mass spectrometry in the case of stable isotopes.

Recently, we have evolved a new approach to absolute fission yield measurements using solid state nuclear track detectors in combination with high resolution gamma ray spectrometry (Ramaswami et al 1979; Iyer et al 1974). This method is particularly suitable for measurement of absolute yields of short-lived fission products which are very important from the point of view of decay heat calculations and which are not easily amenable to measurements by many other currently available techniques. 
The novelty and merit of the technique evolved at Trombay lie in the fact that it eliminates the need for the measurement of neutron flux, fission cross-section, and the exact number of target atoms, thereby eliminating the errors associated with these measurements. The total number of fission $F$ is determined directly with a high degree of accuracy by recording in a mica strip, the number of fissions occurring in a dilute solution of the same target material. The solutions containing the mica strip and the target are irradiated simultaneously in the same irradiation environment. The experimental arrangement is shown in figure 15 .

The total number of fissions $F$ is determined from the measured fission track density, $T d,\left(\# / \mathrm{cm}^{2}\right)$ in the mica strip and from a knowledge of the weight, of the target $W(\mathrm{gm})$, the concentration of the dilute solution, $C\left(\mathrm{~g} / \mathrm{cm}^{3}\right)$ and the track registration efficiency in solution, $K_{\text {wet }}(\mathrm{cm})$, by the equation

$$
F=n \sigma \phi t=\frac{T d \cdot W}{K_{\mathrm{wet}} \cdot C}
$$

The accuracy of the total number of fissions $F$ depends mainly on the value of $K_{\text {wet }}$ which has been determined very carefully in our laboratory (Iyer et al 1974). The advantages of using fission track registration in track detectors immersed in solution as compared to track detectors in contact with a plachetted target (McElory et al 1970; Larsen et al 1972) have been reviewed by Iyer et al (1973), the most significant being increased accuracy and ease of quantitative measurements, both stemming from the uniform distribution of track density on the detector. The method has been applied to obtain a set of absolute fission yields in the neutron induced fission of ${ }^{232} \mathrm{Th},{ }^{233} \mathrm{U}$, ${ }^{295} \mathrm{U},{ }^{239} \mathrm{Pu}$ and ${ }^{245} \mathrm{Cm}$ including the yields of fission products with half lives as short as 7 minutes (Ramaswamy et al 1979, 1980, 1981). Recently, the method has been extended to the spontaneous fission of ${ }^{244} \mathrm{Cm}$ as well (Raghuraman et al 1980). Some

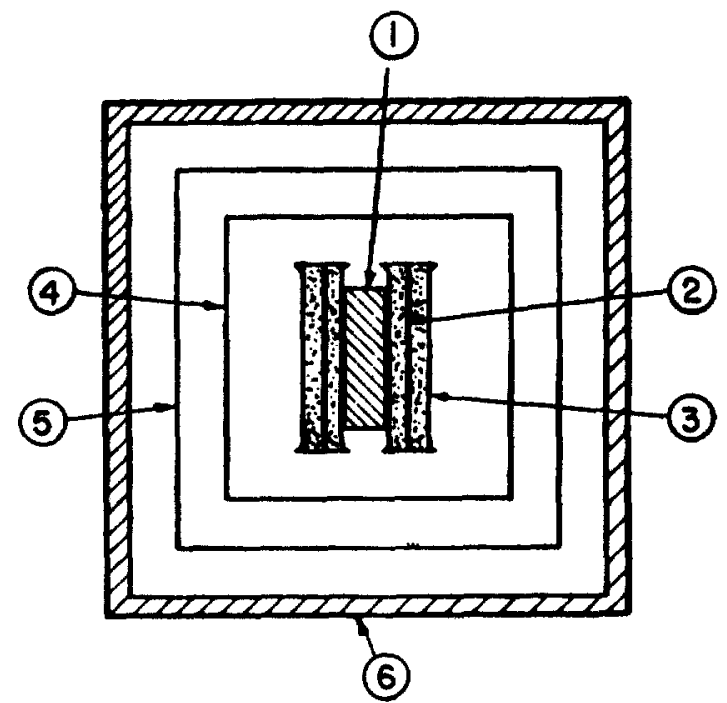

Figure 15. Target-sSNTD arrangement for absolute fission yield measurements: (1) uranyl nitrate sealed in PVC bag, (2) lexan detector immersed in uranyl nitrate solution, (3) polypropylene tube containing uranyl nitrate solution, (4) cadmium foil, (5) sealed pvc bag, (6) harwell aluminium can. 
Table 5. Absolute yields of some short-lived fission products in the neutron fission of ${ }^{203} \mathrm{U}$, ${ }^{295} \mathrm{U}$ and ${ }^{200} \mathrm{Pu} \dagger$

\begin{tabular}{|c|c|c|c|c|}
\hline Fission product & $t_{1 / 2}$ & ${ }^{238} \mathrm{U}$ & $\begin{array}{c}\text { Fission yield }(\%) \\
236 \mathrm{U}\end{array}$ & ${ }^{239} \mathrm{Pu}$ \\
\hline${ }^{87} \mathrm{Kr}$ & $76 \cdot 3 \mathrm{M}$ & - & $2 \cdot 48$ & - \\
\hline${ }^{88} \mathbf{K r}$ & $2.8 \mathrm{H}$ & - & $2 \cdot 86$ & 0.9 \\
\hline${ }^{89} \mathbf{R b}$ & $15.2 \mathrm{M}$ & - & $4 \cdot 44$ & $1 \cdot 46$ \\
\hline${ }^{92} \mathrm{Sr}{ }^{*}$ & $7 \cdot 3 \mathrm{M}$ & - & $6 \cdot 37$ & 3.63 \\
\hline${ }^{104} \mathrm{Tc}^{*}$ & $18 \cdot 2 \mathrm{M}$ & - & $1 \cdot 64$ & 5.69 \\
\hline${ }^{184} \mathrm{Te}^{*}$ & $41.8 \mathrm{M}$ & - & $6 \cdot 8$ & 4.73 \\
\hline${ }^{184} \mathrm{I}$ & $52.6 \mathrm{M}$ & - & $7 \cdot 26$ & - \\
\hline${ }^{138} \mathrm{Cs}$ & $32 \cdot 2 \mathrm{M}$ & 一 & 6.55 & - \\
\hline${ }^{188} \mathrm{Ba}$ & $1 \cdot 4 \mathrm{H}$ & $6 \cdot 25$ & $6 \cdot 34$ & 5.75 \\
\hline${ }^{141} \mathrm{Ba}^{*}$ & $18 \cdot 0 \mathrm{M}$ & - & 5.96 & 5.52 \\
\hline${ }^{142} \mathrm{La}$ & $92.7 \mathrm{M}$ & 6.58 & $5 \cdot 22$ & $4 \cdot 37$ \\
\hline
\end{tabular}

†Source of data: Ramaswami et al (1979, 1980, 1981).

*First reported measurement of absolute yields.

recent data are shown in table 5. In addition to obtaining new experimental fission yield data the SSNTD technique has the potential of being extended to measurement of absolute yields of products with half-lives much shorter than those measured so far.

\section{Future outlook - problems and prospects}

We have had a glimpse of the immense potentialities of solid state nuclear track detectors in probing the many facets of one of the most complex nuclear phenomena, namely nuclear fission. The impact of some of the results obtained through the use of these detectors is indeed far reaching. Any new innovation brings along both promises and challenges: SSNTDS are no exception. A majority of the studies involving tracks of charged particles in SSNTDS is related to the fission process and the presence of these tracks has mainly been used to obtain unambiguos evidence for the occurrence of fission events, with very little effort to precisely identify the particles that caused them. To fully exploit the capabilities of SSNTDs we have to find answers to some of the open problems. A concerted effort on the part of trackologists is needed to precisely identify the charge $(Z)$, mass $(M)$ and energy $(E)$ of the tracks of charged particles in SSNTDs. With recent success in locating newer and better particle track detectors coupled with improvements in track-etching and identification techniques, trackologists have reason to be optimistic about achieving a breakthrough in this area in the coming years. With that, a growing number of exciting new discoveries that depend on a knowledge of $Z, M$ and $E$ of the charged particles are bound to follow.

\section{References}

Anders E and Heyman D 1969 Science 164821

Anders E and Larimer J W 1972 Science 175981

Anders E, Higuchi H, Cros J, Takahashi H and Morgan J W 1975 Science 1901262 
Baran A 1978 Phys. Lett. B76 8

Baran A, Pomovski K, Larson S E, Moller P, Nilsson S G, Randrup J, Lukasiak A and Sobiszewski A 1979 Physics and chemistry of fission, 4th IAEA Symposium, Julich, (Vienna: IAEA) Vol. 1, p. 143

Baumung K 1977 Reactor Dosimetry Proc. Second ASTM-EURATOM Symposium, Palo Alto (Washington: US Nuclear Regulatory Commission) Vol. 2, p. 563

Bjornholm S and Lynn J E 1980 Rev. Mod. Phys. 52725

Brown F, Mardsen D A and Werner R D 1968 Phys. Rev. Lett. 201449

Burnett D S, Gatti R C, Plasil F, Price P B, Swiatecki W J and Thompson S G 1964 Phys. Rev. B134 952

Chaterjee A, Athougies A L, Kailas S and Mehta M K 1981 Phys. Rev. C24 1629

Chaudhuri N K, Natarajan V, Sampath Kumar R, Sagu M L and Iyer R H 1979 Nuclear Tracks 369

Clark D D 1971 Phys. Today 2423

Fairhall A W, Jensen R C and Neuzil E F 1958 Peaceful uses of atomic energy, Proc II UN Conf., Geneva, (Geneva: UN) Vol. 15, p. 452

Ferguson R L, Bemis C E Jr, Plasil F, Silva R J, O'Kelley G D, Hahn R L, Hensely D C, Keifer M L, Mustafa M G, Hulet E K and Lougheed R W 1979 Physics and chemistry of fission, Proc. 4th IAEA Symp., Julich (Vienna: I AEA) p. 208

Fleischer R L, Alter H W, Furman S C, Prize P B and Walker R M 1972 Science 178255

Fleischer R L and Price P B 1964 Phys. Rev. B133 63

Fleischer R L, Price P B and Walker R M 1965 Annu. Rev. Nucl. Sci. 151

Fleischer R L, Price P B anc Walker R M 1975 Nuclear tracks in solids: Principle and application (Berkeley: Univ. of Calif. Press)

Flerov G N, Oganesyan Yu Ts., Lovanov Yu V, Kuznetsov U I, Durin V A, Perelygin V P, Gavrilov K A, Tretiakova S P and Plotko V M 1964 Phys. Lett. 373

Flerov G N, Ter-Akopyan, G M, Popeko A G, Fefilow B C and Subbotin V G 1977 Sov. J. Nucl. Phys. 26236

Flerov G N 1978 Report No. D7-11724 (Joint Inst. for Nucl. Res. Dubna)

Gay R and Sher R 1975 Nuclear crossusection and technology, Washington Conf., NBS Spl. Publ. 425 Vol. 2 p. 587

Hermann G 1979 Report No. GSI-79-7, Gesselschaft fur Scheverionen-Forschung, Darmstadt)

Hoffman D C 1967 Ark Fys. 36533

Hoffman D C 1979 Physics and chemistry of fission, 4th IAEA Symposium, Julich (Vienna: IAEA) Vol. 2 p. 275

Hoffman D C, Weber J, Wilhelmy J B, Hulet E K, Landrum J H, Lougheed $\mathbf{R}$ W and Wild J F 1976 Report LA-UR-76-1055 (Los Almos Laboratory)

Hoffman D C, Wilhelmy J B, Weber J, Daniels W R, Hulet E K, Landrum J H, Lougheed R W and Wild J F 1977, Report LA-UR-77-2901 (Los Almos Laboratory)

Huizenga J R and Vandenbosch R 1962 in Nuclear reactions (ed) P,M Endt and P B Smith (Amsterdam: North Holland) vol. 2, p. 42

Hulet E K, Wild J F, Lougheed R W, Evans J E, Qualheim B J, Nurmia N and Ghiorso A 1971 Phys. Rev. Lett. 26523

Hulet E K, Wild J F, Lougheed R W, Baisden P A, Landrum, J H, Dougan R J, Mustafa M, Ghiorso A and Nitchke J M 1979 Physics and chemistry of fssion, 4th IAEA Symposium, Julich, (Vienna: IAEA) Vol. 2, p. 299

Iyer R H, Sagu M L, Sampath Kumar R and Chaudhuri N K 1973 Nucl. Instrum. Methods 109453

Iyer R H, Sampath Kumar R and Chaudhuri N K 1974 Nucl. Instrum. Methods 11523

Johansson S A E 1959 Nucl. Phys. 12449

Khan H A and Durrani S A 1972 Nucl. Instrum. Methods 98229

Khan H A and Durrani S A 1973 Radiat. Eff. 17113

Lammer $M$ and Leder O J 1973 Nuclear data in scienee and technology (Vienna: IAEA)

Lark N L, Sletten G, Pederson J and Bjornholm S 1969 Nucl. Phys. A139 481

Larsen R P, Dudey N D, Hainrich R R, Armani R J, Gold R, Oldham R D and Popek R J 1972 Trans. Am. Nucl. Soc. 15483

McElroy M N, Kellog L S, Armani R J, Tochilin E and Zimmer W H 1970 Trans. Am. Nucl. Soc. 13868 
Nurmia M, Sikkeland T, Silva R and Ghiorso A 1967 Phys. Lett. B26 78

Nurmia N J 1974 Report LBL-4000 (Lawrence Berkeley Laboratory) p. 53

Otto R J, Morissey D J, Seaborg G T and Loveland W D 1978 Report No. LBL-7710 (Lawrence Berkeley Laboratory)

Polikanov S M, Durin U A, Karnavkhov V A, Mikheev V L, Pelve A A, Skobelev N K, Subbotin V G, Ter-akopyan G M and Fomichev V A 1962 Sov. Phys. JETP 151016

Popeko A G and Ter-akopyan G M 1979 Yad. Fiz. 29604

Raghuraman K, Ramaswami A, Srivastava B K, Natarajan V, Jadhav A V, Sivaramakrishnan C K and Iyer R H 1980 Proc. DAE Symp. on Nucl. and Radiochemistry, Waltair, 147

Raisbeck G M and Cobble J W 1967 Phys. Rev. 1531270

Ramaswami A, Natarajan V, Srivastava B K, Sampath Kumar R, Chaudhuri N K and Iyer R H 1979 J. Inorg. Nucl. Chem. 411531

Ramaswami A, Natarajan V and Iyer R H $1980 \mathrm{~J}$. Inorg. Nucl. Chem. 421213

Ramaswami A, Natarajan V, Srivastava B K and Iyer R H $1981 \mathrm{~J}$. Inorg. Nucl. Chem. (in press)

Randrup J, Tsang C F, Moller P, Nilsson S G and Larson S E 1973 Nucl. Phys. A217 221

Randrup J, Larson S E, Moller P, Nilsson S G, Pomovsky K and Sobiczewski A 1976 Phys. Rev. C13 229

Seaborg G T 1969 J. Chem. Educ. 46626

Turkevich A and Niday J B 1951 Phys. Rev. 8452

Wild J F, Hulet E K, Loaghead R W, Landrum J H, Nitschke J M and Ghorso A 1979 ACS/CSJ Chemical Congress (Abstract-NUCL-64) Honolulu

Zvara L, Flerov G N, Zhuikov B L, Rutz T, Shalaevskii M R 1977 Sov. J. Nucl. Phys. 26240 